\title{
Future Work and Enterprise Systems
}

\author{
Jan vom Brocke - Wolfgang Maaß - Peter Buxmann • \\ Alexander Maedche • Jan Marco Leimeister • Günter Pecht
}

Published online: 25 May 2018

(C) The Author(s) 2018

\section{Introduction}

From its earliest days, research in business and information systems engineering (BISE) has been dedicated to envisioning how information technology will change the way we work and live. Today, technological innovation happens at a faster pace and reaches users more quickly than ever before. For example, while it took 75 years for the telephone to reach 100 million users, it was 16 years for mobile phones, 7 years for the World Wide Web, four and

\section{J. vom Brocke $(\square)$}

Hilti Chair of Business Process Management, University of Liechtenstein, Fürst-Franz-Josef-Strasse 21, 9490 Vaduz, Liechtenstein

e-mail: jan.vom.brocke@uni.li

W. Maaß

Saarland University, Saarbrücken, Germany

W. Maßß

German Research Center for Artificial Intelligence (DFKI),

Saarbrücken, Germany

P. Buxmann

TU Darmstadt, Darmstadt, Germany

A. Maedche

Karlsruhe Institute of Technology (KIT), Institute of Information

Systems and Marketing (IISM), Karlsruhe, Germany

J. M. Leimeister

University of St. Gallen, St. Gallen, Switzerland

J. M. Leimeister

University of Kassel, Kassel, Germany

G. Pecht

SAP SE, Walldorf, Germany a half years for Facebook (Dreischmeier et al. 2015), and only a few weeks for Pokémon GO (Moon 2016).

The rapid acceleration of technological diffusion confronts BISE researchers, who usually study technological innovations from the perspective of socio-technical systems (Bostrom and Heinen 1977). Work systems are conceptualized as an interplay of tasks, technologies, and people (vom Brocke and Rosemann 2014), systems "in which human participants and/or machines perform work (processes and activities) using information, technology, and other resources to produce specific products/services for specific internal and/or external customers" (Alter 2013, p. 75).

Against this background, much of the current discourse about future work systems addresses automation, as work is increasingly performed by machines. For example, blockchain and smart contracts can automate large parts of the supply chain (Mendling et al. 2018), and machine learning now facilitates automation in business areas that were once too unstructured for automation (Willcocks et al. 2015). In such settings, people are likely to contribute to work systems by means of creative work and exploration (as opposed to exploitation), a distinction that O'Reilly and Tushman (2013) referred to as organizational ambidexterity. Therefore, from the perspective of BISE research, the future of work poses questions about the interplay of people and machines, as Lehrer et al. (2018) outlined in their work on digital service innovation.

In this discussion, we differentiate between the social intensity and the technical intensity of work and define four basic types of work systems, as shown in Fig. 1.

Figure 1 shows that, at a basic level, work systems can be organized along two dimensions, social intensity and technical intensity, with high social intensity meaning that the work is highly dependent on human factors like trust. 


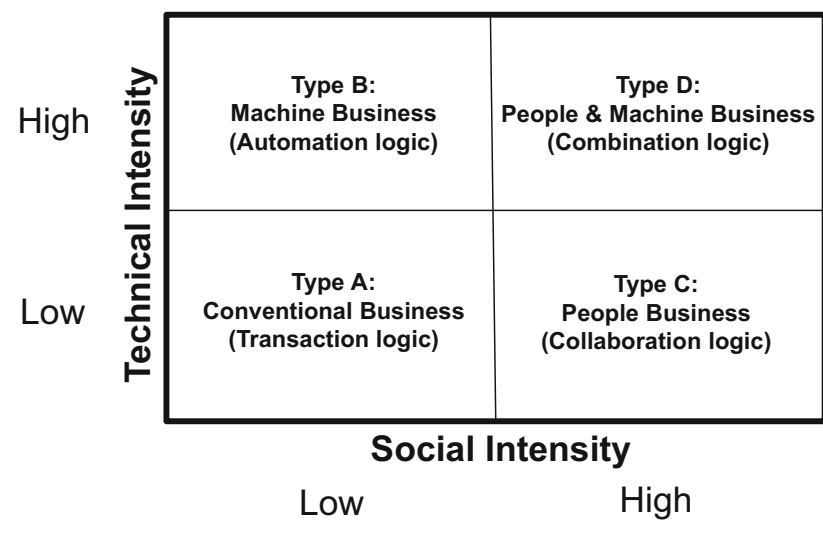

Fig. 1 Four types of future work systems

Along these dimensions, four types of work systems may be differentiated, each characterized by an underlying "logic" of work (see also Tumbas et al. 2018).

- Type A Systems with comparatively low social and technical intensity may be referred to as "conventional businesses." Enterprise resource planning (ERP) systems are examples of systems that follow a logic of workflows (transactions) conducted by people and machines. Most organizations today consider such systems part of their core business (vom Brocke et al. 2017).

- Type $B$ The automation of work systems through innovative technology marks an avenue for future work systems that may be referred to as "machine businesses," which are characterized by high technical intensity and low social intensity. Flight-booking services that compare thousands of offers in fractions of a second are examples of machine businesses. Research on blockchain and smart contracts will automate large areas of administrative work in most organizations' supply chains (Mendling et al. 2018).

- Type C An important contribution people can make to man-machine environments is to bring in human capabilities like creative thinking and social behavior. Thus, services that are characterized by high social intensity and low technical intensity, which we refer to as "people businesses," mark another avenue for future work systems. Counseling work is an example of high social-intensity work, as is organizational leadership. The logic is that of people interacting in a collaborative setting.

- Type $D$ Several areas in today's businesses have elements of both machine business and people business, and we refer to these as "machine and people businesses." For example, robo-advising automatically identifies and compares investment opportunities based on the user's preferences. However, since financial investments have affective impacts on investors and still require human work, such services often also have high levels of social intensity. Therefore, innovative technological services and value-adding social services should be combined in hybrid arrangements of man and machine, where people may interface with both users and machines by, for example, selecting trustworthy machines and explaining and contextualizing the results. In this regard, automation can assist human actors in improving service to customers and society.

Machines will deliver larger parts of work in the future, which will challenge humans to provide added value but will also provide opportunities to do so and to create new levels of value. Consider the example of university lectures: Online lectures are a good example of the transfer of technical knowledge via digital-learning resources like massive open online courses (MOOCs), while in-class learning experiences can focus on discussions and project work that cannot be experienced in online environments at the same level of quality (Winter et al. 2015). Eventually, such socio-technical systems may improve outcomes, such as providing richer learning experiences at universities, but they also challenge the employees who are involved in delivering such services. An important area of future BISE research is to explain how such hybrid combinations of people and machines contribute to businesses and to design innovative and value-adding business models through these combinations.

The following discussion focuses on several aspects of future work. First, Wolfgang Maaß, of Saarland University and the German Research Center for Artificial Intelligence (DFKI), takes a closer look at artificial intelligence and its effects on future work systems (Type B). Then Peter Buxmann, of the Technical University of Darmstadt, discusses social collaboration tools, taking the perspective of people businesses (Type C). Alexander Maedche, of the Karlsruhe Institute of Technology, follows with a characterization of Intelligent Enterprise Systems, in which, as opposed to conventional ERP Systems (Type A), both machines and people interplay in new forms of value creation (Type D). Next, Jan Marco Leimeister, of the University of St. Gallen and the University of Kassel, focuses on crowdsourcing as a design principle of future work, showing ways of combining machine and people businesses (Type D). The contribution from Günter Pecht, Global Vice President of SAP SE, rounds out the discussion, adding a practice perspective to the interplay of man and machine in future work and enterprise systems (Type D).

Jan vom Brocke University of Liechtenstein 


\section{Artificial Intelligence and Future Work}

The influence of IT technologies and in particular Artificial Intelligent (AI) technologies on the future of work develops along the innovation axis of optimization - transformation - disruption. The rapid development of AI technologies in recent years has created a great deal of uncertainty about the implications for the future of work (Brynjolfsson and McAfee 2014). Technological unemployment can be framed as positive, long-standing human project: "The increase of technical effciency has been taking place faster that we can deal with the problem of labour absorption" (Keynes 1930 in Floridi 2014).

Artificial Intelligence has worked with logical and statistical truth concepts from the beginning (Russell and Norvig 2009). Artificial neural networks (ANN) and statistical learning were studied as early as the 1960 s but disappeared in the late 1990s due to lack of efficiency and inadequate scalability (Schmidhuber 2015). Semantic approaches, on the other hand, have been used ever since and were able to achieve numerous successes, such as in speech processing (Wahlster 2013). The landscape of different artificial intelligence technologies developed over decades in Germany and is currently experiencing tremendous acceptance in various industries. Essential for this is the availability of efficient infrastructures and the rapid development of robust and scalable algorithms. Important drivers are technologies, such as supervised and non-supervised learning including various variants of deep learning and reinforement learning (Schmidhuber 2015).

Artificial intelligence technologies are currently successful in regulated environments, such as games, e.g., the game of Go (Silver et al. 2017). At the threshold between research and application, AI systems enable autonomous actions, such as autonomous driving. The same is true for work situations in which humans and robots collaborate. Robotic Process Automation (RPA) uses AI technologies to bring decision-making intelligence, flexibility and adaptability into business process environments. Today, ANN create "black boxes" which bury decision-making knowledge in the depths of statistical networks (Hastie et al. 2001), partially handed over to external operators so that companies no longer master data and knowledge themselves. Consequently, decisions cannot be explained or understood, which raises many strategic and legal questions.

A large part of current AI projects addresses the optimization of existing business tasks. Exemplary are chat bot projects in order to optimize customer contact in call centers. The often mentioned predictive maintenance projects also target the reduction of maintenance costs. Significantly fewer activities can be found in the field of transformation. Industry 4.0 is above all a transformational approach which changes mass production into individual production (Kagermann et al. 2013). Thus, Industry 4.0 is the provision of individual product service systems at the marginal costs of mass production. Examples of innovative transformation initiatives include the Internet of Things (IoT) platforms by multinational enterprises. By AI-based transformation initiatives, these companies start to explore novel business models with unforeseeable repercussions on traditional business models. These initiatives are often driven by the understanding that profit margins of traditional products are decreasing and that only smart services will create growth opportunities.

Naturally, there are far fewer examples in the field of disruption. Uber's autonomous vehicles are a disruption to the global mobility market. As Cramer and Krueger (2016) show, AI technologies for matching customers and Uber taxis, dynamic pricing and ease-of-use for disruption are critical.

Along the transformational axis of optimization, transformation and disruption are effects of AI-based technologies on the future of direct and indirect work. Direct effects on existing work are evident in the area of optimization. Chat bots in call centers are either used to intensify customer contact or reduce costs. In the first case, call center agents provide higher-value services whereas the second case leads to staff reductions. Consequently, the future of optimization of work is driven by the conflicting goals of quality and cost efficiency.

In terms of transformation, direct effects are divided into two parts. On the one hand, transformational business model innovations create new jobs, for example, to develop and to operate IoT platforms and services. If these impede the reduction or even abandonment of existing business models and related products and services, there will be negative impacts on jobs. However, such developments are mostly market-driven and not directly driven by AI-based services. As a result, the transformation creates a trade-off between existing and innovative business models.

A disruption has an immediate, direct impact. Wherever Uber or Lyft operates, taxi companies suffer from heavy pressure. Should the taxi industry not transform itself fundamentally, many taxi companies will disappear from the market.

Developments show that indirect effects on work in the field of optimization are rather unlikely, as they are more local in nature. For example, optimization of production processes by predictive maintenance does not affect sales organizations. The situation is different for transformation. The development of innovative product service systems often leads to changes in existing business models. Staff cuts and shifts to other areas happen when products and services are abandoned. Since such changes affect all areas of a company, adaptation measures must be planned and 
implemented early on. Indirect effects induced by disruptions are difficult to anticipate, which mostly leads to reactive adaptation measures. The impact that autonomous vehicles will have on the automotive market, for example, can hardly be foreseen.

How can companies and industries react to the impact of AI technologies? As indicated, the use of AI technologies in optimization is local in nature with little indirect impact. Traditional retraining measures can be used. In contrast, transformation often results in large direct and indirect changes in the organization of work. It can be assumed that major conflicts will arise when companies and whole industries are slow in implementing transformation initiatives supported by the creation of new job profiles and major investment in skill developments. For example, statistical analysis of data streams enables companies to quickly respond to individual customer requirements. This requires transformation initiatives in all areas of a company, including marketing, sales, human resources, and general administration. Therefore it is important to refocus corporate strategies, train workers to meet these changing needs, reorganize corporate organizations, and transform product and service offerings.

Wolfgang Maaß

Saarland University and

German Research Center for Artificial

Intelligence (DFKI)

\section{Social Collaboration Tools and the Future Work}

\subsection{Social Collaboration Tools and the Emergence of Social Collaboration Platforms}

Social Collaboration (SC) tools are increasingly becoming crucial parts of nowadays organizations. We refer to them as tools that are aimed at fostering communication and collaboration among employees (see also Richter et al. 2011). For instance, this definition includes instant messaging (e.g., Slack or Microsoft Teams), social networking (e.g., Workplace by Facebook or IBM Connections) and group collaboration tools (e.g., Atlassian Confluence or Microsoft SharePoint). While different types of SC tools have initially been considered separately, an increasing combination of their features into holistic SC platforms can be observed. Against this backdrop, both theoretical and practical perspectives emphasize the particular value of social media features that most employees know well from their private lives and that offer them the possibility to engage in organizational discussions actively.
3.2 The Importance of Social Collaboration Tools for the Future of Work

The increasing introduction and utilization of SC tools are likely to contribute to the future of work that we will soon experience. In particular, we see three reasons why dealing with SC tools is essential. First, they can be used for a variety of different use cases. While traditional IS like CRMs or ERPs have been developed to address well-defined tasks and processes, SC tools exhibit the characteristics of "malleable software" (Richter and Riemer 2013). Malleable software can be utilized in many ways, enabling a variety of benefits. Although identifying suitable use cases represents a challenge for some companies, it offers them the opportunity to refine the ways how they use SC tools continuously. Along these lines, prior research has started to differentiate different types of usage to help companies to understand and implement SC tools better (e.g., Schlagwein and $\mathrm{Hu} 2016$ ).

Second, as a result of the use cases' variety, SC tools impact organizations at different levels. On the individual level, employees can profit from efficient ways to access knowledge and organization-related news. On the group level, teams can benefit from faster decision processes and an improved management of project plans, documents, and tasks. On the organizational level, companies can profit from the comprehensive exchange of information and knowledge across borders, enabling innovation on a large scale. As a result, SC Tools affect not only common performance measures but also the underlying cultural aspects of how a company works.

Third, realizing the benefits of SC tools requires organizations to develop elaborated collaboration strategies. While many companies assume that providing access to SC tools is enough to leverage their full potential, reality often challenges this assumption (Leonardi and Neeley 2017). Consequently, it is essential to thoroughly understand how to introduce, implement, and integrate SC tools. A particular factor, again, refers to cultural aspects and the questions of how employees perceive the systems and their use cases. By digging deeper into this direction, prior research began to examine the conditions under which employees refuse to participate in SC tools (e.g., Choudrie and Zamani 2016; Gibbs et al. 2013) to help companies to get them on board. For instance, a recent study by Huang et al. (2015) showed that companies even benefit from leisure-related postings as positive spillover effects improve their employees' consumption of workrelated content. 
3.3 The Impact of Social Collaboration Tools on Innovation, Hierarchies, and Employee Integration

However, if organizations handle the challenges successfully, the benefits of SC Tools can be significant. In particular, we would like to highlight three potentials that have been empirically underpinned lately. A first benefit refers to Leonardi's work $(2014,2015)$, which provided evidence that ESNs enable employees to become aware of their colleagues' conversations. The underlying concept has been named communication visibility. Based on their communication awareness, employees can gain knowledge about their co-workers (i.e., meta-knowledge). In Leonardi's case, the improvements of employees' metaknowledge reached up to $88 \%$. A strong meta-knowledge allows employees not only to reduce duplicated work due to a better overview of the companies' activities but also to be more innovative as they have access to more of the companies' ideas, which can be reused in new contexts. However, even if communication across entire organizations is not possible, prior research emphasizes the potential of generating ideas based on a deeper understanding of a company's particular area (Rhee and Leonardi 2018), which is also enabled by a good team- or department-wide communication. Against this background, an interesting question is how to trade-off both ways of innovating if employees have to split their attention between organization- and department-wide communications.

A second benefit refers to the potential of ESNs to change existing hierarchies. Accordingly, Riemer et al. (2015) showed that ESNs lead to more balanced communication structures when the systems are utilized in the long run. In the short run, employees' influence is still derived from formal positions. Fostering more balanced structures should be desirable for most employees, as it offers them a chance to overcome inherent restrictions of hierarchies. However, dealing with managers' changing roles is a new challenge that emerges from this transformation. Further research on this issue is still necessary.

A third potential concerns the integration of new employees into organizations, which is especially important given the increasing number of job changes many employees encounter. Koch et al. (2012) found that new hires profit from ESNs as they can better connect with their co-workers, which decreases the rate of employees who resign. An important requirement for this benefit is the occurrence of both private and work-related communication in the system. The fact that Koch et al. (2012) also reported that middle managers had a hard time to redefine their roles regarding the integration of new hires again emphasizes the importance of managing change associated with the use of SC tools.
In conclusion, the potentials of SC tools to shape the future of work are vast. In particular, the complex intersection of technological advances, the transformation of organizational cultures and structures as well as the continuous development of employees' expectations and abilities unleashes a variety of research opportunities.

Peter Buxmann

TU Darmstadt

\section{Intelligent Enterprise Systems}

Driven by globalization, technological progress and demographic change, the "Future of Work" is currently intensively discussed in practice and science influencing both the quantity and quality of the future work environment. Whereas technology pioneers frequently believe that the human workforce will soon be substituted by selflearning robots, this belief has yet to prove itself true. From my perspective, the information systems (IS) discipline is in a strong position to contribute with its research to a better understanding and design of the future work environment with a specific focus on the IT artefact and its interplay with the corresponding "workers". In this discussion section, I want to particularly concentrate on the question how future Intelligent Enterprise Systems (IES) should be designed and implemented in order to meet defined socio-economic goals.

\subsection{What are Intelligent Enterprise Systems (IES)?}

Enterprise Systems (ES) refer to specific IS denoted as the backbone of enterprises' operations with a high integration level and great multi-dimensional impact. Historically, the term ES has often been used as a synonym for packaged application software, such as Enterprise Resource Planning (ERP) or Customer Relationship Management (CRM) (Liang et al. 2007). With the blurring boundaries of transactional-, analytical-, and people-centric systems, nowadays the term ES covers all organizational-wide IS as well as associated platforms. Specifically, I consider ES as a socio-technical phenomenon (Lauterbach et al. 2013) which equally accounts for the individual, technological, and organizational elements involved in helping to advance both economic and humanistic benefits (Sarker 2011). However, in the years ahead, ES will be subject to significant changes as we see more applications empowered by artificial intelligence (AI), primarily due to substantial advancements in machine learning algorithms. Areas such as natural language processing, deep neural networks, or self-service analytics are probably some of the prime beneficiaries of machine learning applications. By adding 
AI capabilities to ES, they are enabled to sense and dynamically respond to their environment as well as continuously learn. The evolving Intelligent Enterprise Systems (IES) will represent a new class of systems and become a key element in the future work environment.

\subsection{Which Socio-economic Goals Should be Pursued?}

It is important to emphasize that different types of goals may be pursued by information systems in general (Sarker 2011), and IES specifically. By improving existing business processes and models or setting the terms for new ones, IES are geared at boosting the value added and thus improving business results. From an economic stance, IES aim to increase productivity, for instance, by enabling full automation of selected tasks. Besides full automation, it may also be a goal to increase task performance in humansystem cooperation. Further, employees increasingly voice the need for meaningfulness, participation, and empowerment in their work environment. In this line, IES may also contribute to humanistic goals, such as emphasizing individual human values or helping employees find a better balance between work and life.

\subsection{What are Challenges for the Design of IES?}

The design of IES comes with many interesting challenges for IS research. One important area is proposing design principles for interactive IES. One example is the design of conversational interfaces in IES, offering text- and speechbased interaction with its users (Gnewuch et al. 2017). A second, more specific example is the design of interactive design elements in Business Intelligence and Analytics systems that actively involve the user at different stages in the data-analysis lifecycle in order to increase trust and understanding of the corresponding decision support feature. Interactive machine learning techniques give "power to the people" by enabling an interactive examination of the computed models through trial-and-error in an incremental manner (Amershi et al. 2014).

Another important area is the measurement and processing of cognitive-affective states of employees. New hardware devices in combination with real-time data processing capabilities will make it possible to dynamically individualize and adapt IES to their users. Intelligent Enterprise Systems such as predictive maintenance systems collect and process large amounts of data in real-time. Users must be capable of processing this vast amount of presented data without considerable cognitive effort. Operational decision makers' situation awareness may be promoted by following a design paradigm which allows human beings to understand and anticipate the available information effectively (Nadj et al. 2016). Another example of one currently ongoing research project with our research group is the monitoring and prediction of flow states of employees based on physiological data (Rissler et al. 2018). These results can serve as a fundament to develop flow-aware IES capable of automatically identifying flow in real-time and inducing better and/or longer flow experiences at work. Particularly, a "flow-aware" IES could be developed to prevent an employee from being interrupted in the middle of an ongoing task by guaranteeing that no e-mails or notifications are forwarded as long as the IES is "sensing" flow.

\subsection{What are Challenges for the Implementation} of IES?

Well-designed IES will only contribute to the defined socio-economic goals if they are successfully implemented into organizations. This requires a much deeper understanding of the interplay of technological elements with the individual and organizational elements of an IES. For example, embedding real-time operational analytics capabilities in transactional work requires the employees to have the necessary competencies to actually make decisions and take actions. Furthermore, the technological capabilities of IES make organizations flatter and more agile, however, this simultaneously also requires new organizational designs.

IES come with many opportunities for the future work environment. In the effort to address the challenges in the design and implementation of IES, I see the socio-technical mindset of the IS research community as a unique differentiator and a critical facet for the "Future of Work".

Alexander Maedche

Karlsruhe Institute of Technology (KIT)

\section{How Crowdsourcing is Changing the Future of Work}

\subsection{Introduction}

In the context of digitization, companies will face increasingly volatile, uncertain, complex and ambiguous (VUCA) business environments. They attempt to deal with the new challenges by increasing their flexibility, agility and speed, which will lead to profound changes in the world of working. Our world is much more interconnected - anytime and anyplace - thus enabling new ways of working and new forms of dividing labor (Brynjolfsson and McAfee 2014). One form that has strongly grown in popularity is crowd work. It describes a novel way of organizing work and constitutes a solution for new challenges, because it can process work faster, cheaper and in a more 
flexible way compared to 'traditional' settings. Crowd work is a digital form of gainful employment that is based on the principles of crowdsourcing to orchestrate a mass of people via an open call on IT-facilitated platforms to create digital goods (Durward et al. 2016).

Crowd work can be applied within (internal crowd work) and beyond organizational boundaries (external crowd work), and sometimes we even see combinations of these ways of organizing work (hybrid or mixed mode crowd work). Examples are manifold, such as Airbus applying crowdsourcing principles for engineering work in order to develop a cargo drone for civil purposes (delivery of medicine). Using the crowd working platform "Launch Forth" of Local Motors, several hundred crowd workers developed the cargo drone in collaboration with each other and with support of Airbus' employees. This drone was developed at lower costs within several weeks via crowd work compared to 1 year using the existing internal Airbus processes.

Internal crowd work is also used in other ways and delivers outstanding results. For instance, a Swiss bank developed its new core banking system with its help - an immensely complex project with far reaching effects on almost all future processes, products and even the business model. The overall project followed an agile approach with 2 week sprints. In order to test the software as well as the underlying business logic, the bank used internal crowd testing. The bank invited its own employees through an open call to test the software via an internal IT-platform every 2 weeks. Several hundred employees participated regularly and voluntarily (Knop et al. 2017). Effects were a higher quality of the software (less bugs, better interfaces, etc.) but also better business logic and processes, due to the rich pool of expertise and large size of the crowd. Furthermore, this approach prepared the organization better for the organizational change by simultaneously integrating large parts of the overall workforce into such technochange projects (Markus 2004).

Both examples - Airbus and the Swiss Bank - use platforms as intermediaries and thereby highlight a trend towards "platformization". Many of the worldwide leading companies, especially in consumer markets, have based their business model on platforms. One can distinguish between three kinds of platforms: Commerce platforms (e.g., Amazon or Alibaba), sharing platforms (e.g., Airbnb or Uber) and crowd working platforms (e.g., Amazon Mechanical Work or Upwork) (Mras et al. 2017). The latter - crowd working platforms - are the "enablers" of crowd work, the novel form of work organization. With their technical features, they also provide large potential for automation of work. They orchestrate a work system that can be classified as a "People and Machine Business (type
C)"-work system that is characterized by both a social and a high technical intensity.

\subsection{Implications for the Future of Work}

The rise of crowd work and corresponding platforms provide additional ways of organizing and processing work. Organizations can choose among these different types of processing and must constantly evaluate which form is best suitable for a certain work (i.e., the classic "market versus hierarchies" decision, see also Williamson 1975). If there is for example a high need for confidentiality or contractual relationships, processing within a company might be the best solution. If a company wants to exploit specialized knowledge at relatively low costs, outsourcing work to a specialized firm might be a good choice. And lastly, if a company wants to tap into the potential of a vast number of contributors, for example to increase the heterogeneity of solutions and therefore foster innovation, mandating a crowd working platform could be a very valuable option.

\subsection{What's Next?}

In sum, crowd work represents a principle of work organization that has the potential to change the nature of value creation in a disruptive way since it fundamentally changes the distribution of work and collaboration among workers. IS research is well equipped to address this issue and to leverage its body of knowledge to design this new form of digital work. The digital work design is at the very core of our discipline (Richter et al. 2018), and guidelines for empowerment-oriented and decent crowd work should be developed to leverage its full potential. In this context a systematic empowerment of employees represents a central success factor to facilitate innovation power, agility, flexibility, and competitiveness. Crowd work can only be used effectively on the basis of the workforce's communication, creativity and decision-making autonomy of the workforce. On the one hand, IS research should help design digital work systems that enable organizations to benefit from the potentials of crowd work. On the other hand, it should ensure good and fair working conditions for individual crowd workers. The design of appropriate incentive and remuneration mechanisms as well as effective collaboration structures among participants will be necessary. Human-centric, effective digital work systems consider how a systematic empowerment of companies and employees can be implemented to enable both, work satisfaction of employees as well as the effective and efficient achievement of organizational goals. IS research should inform stakeholders (organizations, unions, policy makers, 
etc.) on how to design good digital work systems for building a better future.

Jan Marco Leimeister University of St. Gallen and University of Kassel

\section{The Human Side of Digitization}

\subsection{How to Flex in a World of Flux}

We know digital transformation is already impacting workplaces globally. Since 2000, 52\% of the Fortune 500 have either experienced bankruptcy, been taken over, or gone out of business entirely. The speed of innovation is increasing exponentially, and new technologies like the Internet of Things, artificial intelligence and robotics are making it possible to automate routine tasks. As these technologies become more widely adopted, efficiency will no longer be a key differentiator for enterprises. Instead, today business leaders are looking for warp-speed innovation and productivity increases of 25-30\%. They are achieving it by combining the Internet of Things, artificial intelligence, and other digital technologies.

The companies with the best performance use digital technologies to pull away from the rest. According to IDC (2017), worldwide spending on digital transformation technologies is projected to grow exponentially (to $\$ 2.1 \mathrm{~T}+$ by 2019). But, perhaps surprisingly, technology is not the starting point of the discussion amongst successful digital leaders.

\subsection{Dismantling Industrial-Age Management Practices}

Instead, leaders are asking how to create work environments that enhance the unique human ability to innovate, in our increasingly automated world? They realize that 19th-century command and control management approaches are not the ones that will unleash the 21st-century human ingenuity which is required. Industrial-age practices served companies well as long as a low degree of automation, a poorly educated workforce doing manual tasks, and ill-informed customers in stable mass markets were the norm. Today, a highly-educated workforce, perfectly informed customers, and hyper-automation are forcing companies to radically rethink their management practices.
6.3 Enhancing the Unique Human Ability to Innovate

In a world where everything that can be automated will be automated, organizations will need to become more human than ever. The human abilities to create with passion, to empathize, to collaborate and to innovate is the competitive edge humans still have over machines. However, today's enduring management practices do more to encourage employee obedience, diligence and expertise than to tap their higher-level values like passion, creativity and initiative (Hamel 2012). It's obvious that we can't respond to these new challenges with traditional management approaches. More creative work done by diverse workgroups requires more flexible, collaborative and open structures. Finding new ways of coordinating work across organizational silos and unleashing human creativity and passion is no longer a luxury, it's an imperative. Futurefocused leaders understand that they need to:

1. Adopt a leadership style that leaves room for experimentation and for making mistakes along the way. Innovative teams encourage and thrive on a diversity of backgrounds, perspectives, and personalities.

2. Enable everyone to understand the organization's purpose. Companies that follow this kind of purposeled approach look at business differently. Instead of viewing business transactions as win/lose, purpose-led companies understand how everyone can benefit. With this mindset, employees are value contributors, customers are advocates, suppliers are business partners, and goals embrace the triple bottom line - economy, society, and environment. Data shows that purpose-led companies outperformed the S\&P 500 by 10 times between 1996 and 2014.

3. Empower people to be creative and take action to achieve goals. Ensure leaders 'get out of the way' and encourage people to take the initiative to look for ways to help the company thrive whenever they see an opportunity. Empower distributed decision intelligence to increase decision quality and foster ownership and autonomy. Give more decision-making powers to the people who are affected by the decisions. Empower employees, put them into charge, give them more freedom, but also ask for more self-responsibility in return.

4. Organize differently. Innovative companies have more fluid structures. Employees form dynamic teams to address opportunities and set their own paths to achieving objectives. Teams include all the roles that are necessary for the company to succeed, and are set up to ensure end-to-end responsibility for achieving objectives and customer demands. 
5. Consider the team setup carefully to foster more accountability and autonomy. Not only 'who' is on a team, but 'how' they got there is important. Provide opportunities for people to choose their project assignments. Enable self-assignment to tasks and responsibilities, recognizing that people are more motivated when they decide where their unique talents can best contribute.

6. Understand that peer group competition and team pressure are powerful motivators. In self-managed teams, the onus on "doing the right" thing for the team is high because members have a lot more information. For example, the temptation for members to blow the budget on that first-class plane trip is low, since the team also possesses insight into the budget spending. Therefore, replace today's traditional management controls with mechanisms that promote more information-sharing within the team. Also, people tend to compare their own group's performance with the performance of other teams. Thus, healthy competition among peer groups keeps people focused on helping each other succeed in their team's mission.

The SAP Future of Work team helps companies tap the unique human capacity to innovate by developing technology solutions that make it easier for companies to embrace new management practices and new ways of working. SAP Work-Life stands out, among the many software innovations that our team is developing, as an example of how our solutions enable companies to put people first. Other solutions currently being developed by our team include approaches to transform the way individuals and organizations learn and develop competencies, increase internal job mobility (job trading), and help selfmanaged teams effectively plan their resources.

Günter Pecht

\section{Global Vice President SAP SE}

Open Access This article is distributed under the terms of the Creative Commons Attribution 4.0 International License (http://crea tivecommons.org/licenses/by/4.0/), which permits unrestricted use, distribution, and reproduction in any medium, provided you give appropriate credit to the original author(s) and the source, provide a link to the Creative Commons license, and indicate if changes were made.

\section{References}

Alter S (2013) Work system theory: overview of core concepts, extensions, and challenges for the future. Bus Anal Inf Syst 14(2):72

Amershi S, Cakmak M, Knox WB, Kulezsa T (2014) Power to the people: the role of humans in interactive machine learning. AI Mag 35(4):105-120
Bostrom R, Heinen J (1977) MIS problems and failures: a sociotechnical perspective, part II: the application of socio-technical theory. MIS Q 1(4):11-28

Brynjolfsson E, McAfee A (2014) The second machine age: work, progress, and prosperity in a time of brilliant technologies. Norton, New York

Choudrie J, Zamani ED (2016) Understanding individual user resistance and workarounds of enterprise social networks: the case of Service Ltd. J Inf Technol 31(2):130-151

Cramer J, Krueger AB (2016) Disruptive change in the taxi business: the case of Uber. Am Econ Rev 106(5):177-182

Dreischmeier R, Close K, Trichet P (2015) The digital imperative. bcg perspectives. The Boston Consulting Group Inc. http:// image-src.bcg.com/Images/The_Digital_Imperative_Mar_2015_ tcm9-80124.pdf. Accessed 25 Mar 2018

Durward D, Blohm I, Leimeister JM (2016) Crowd work. Bus Inf Syst Eng 58(4):281-286

Floridi L (2014) Technological unemployment, leisure occupation, and the human project. Philos Technol 27(2):143-150

Gibbs JL, Rozaidi NA, Eisenberg J (2013) Overcoming the "ideology of openness": probing the affordances of social media for organizational knowledge sharing. J Comput Mediat Commun 19(1):102-120

Gnewuch U, Morana S, Maedche A (2017) Towards designing cooperative and social conversational agents for customer service. In: Proceedings of the 38th International Conference on Information Systems (ICIS), Seoul, ROK, December 10-13, 2017

Hamel G (2012) What matters now: How to win in a world of relentless change, ferocious competition, and unstoppable innovation. Jossey-Bass, San Francisco

Hastie T, Tibshirani R, Friedman J (2001) The elements of statistical learning. Springer, New York

Huang Y, Singh PV, Ghose A (2015) A structural model of employee behavioral dynamics in enterprise social media. Manag Sci 61(12):2825-2844

IDC (2017) FutureScape: Worldwide IT industry 2017 prediction. https://www.idc.com/getdoc.jsp?containerId=US41883016. Accessed 22 Apr 2018

Kagermann $\mathrm{H}$ et al (2013) Umsetzungsempfehlungen für das Zukunftsprojekt Industrie 4.0: Deutschlands Zukunft als Produktionsstandort sichern; Abschlussbericht des Arbeitskreises Industrie 4.0. https://www.bmbf.de/files/Umsetzungsempfehlun gen_Industrie4_0.pdf. Accessed 8 May 2018

Knop N, Durward D, Blohm I (2017) How to design an internal crowdsourcing system. In: International conference on information systems, Seoul

Koch H, Gonzalez E, Leidner D (2012) Bridging the work/social divide: the emotional response to organizational social networking sites. Eur J Inf Syst 21(6):699-717

Lauterbach J, Kahrau F, Maedche A, Mueller B (2013) Reconceptualizing enterprise systems. In: Proceedings of IFIP 8.2 PreICIS workshop on organizations and society in information systems, Milan

Lehrer C, Wieneke A, vom Brocke J, Jung R, Seidel S (2018) How big data analytics enables service innovation: materiality, affordance, and the individualization of service. J Manag Inf Syst (JMIS) (forthcoming)

Leonardi PM (2014) Social media, knowledge sharing, and innovation: toward a theory of communication visibility. Inf Syst Rev 25(4):796-816

Leonardi PM (2015) Ambient awareness and knowledge acquisition: using social media to learn "who knows what" and "who knows whom". MIS Q 39(4):747-762

Leonardi P, Neeley T (2017) What managers need to know about social tools: avoid the common pitfalls so that your organization 
can collaborate, learn, and innovate. Harv Bus Rev 95(6): 118-126

Liang H, Saraf N, Hu Q, Xue Y (2007) Assimilation of enterprise systems: the effect of institutional pressures and the mediating role of top management. MIS Q 31(1):59-87

Markus LM (2004) Technochange management: using IT to drive organizational change. J Inf Technol 19(1):4-20

Mendling J, Weber I, van der Aalst W, vom Brocke J et al (2018) Blockchains for business process management - challenges and opportunities. ACM Trans Manag Inf Syst 9(1):1-16

Moon M (2016) 'Pokémon Go' hits 100 million downloads. engadget, 8 January 2016. https://www.engadget.com/2016/08/01/poke mon-go-100-million-downloads/. Accessed 25 Mar 2018

Mras V, Li MM, Peters C (2017) Towards a taxonomy of digital work. In: 25th European conference on information systems, Guimarães, pp 2515-2524

Nadj M, Jegadeesan H, Maedche A, Hoffmann D, Erdmann P (2016) A situation awareness driven design for predictive maintenance systems: the case of oil and gas pipeline operations. In: Proceedings of the 24th European conference on information systems, Istanbul

O'Reilly CA, Tushman ML (2013) Organizational ambidexterity: past, present and future. Acad Manag Perspect 27(4):324338

Rhee L, Leonardi PM (2018) Which pathway to good ideas? An attention-based view of innovation in social networks. Strateg Manag J 39(4):1188-1215

Richter A, Riemer K (2013) Malleable end-user software. Bus Inf Syst Eng 5(3):195-197

Richter D, Riemer K, vom Brocke J (2011) Internet social networking: research state-of-the-art and implications for enterprise 2.0. Bus Inf Syst Eng 3(2):89-101

Richter A, Heinrich P, Stocker A, Schwabe G (2018) Digital work design. Bus Inf Syst Eng 60(3)

Riemer K, Stieglitz S, Meske C (2015) From top to bottominvestigating the changing role of hierarchy in enterprise social networks. Bus Inf Syst Eng 57(3):197-212
Rissler R, Nadj M, Li MX, Knierim MT, Maedche A (2018) Got flow? Using machine learning on physiological data to predict flow. In: Proceedings of $2018 \mathrm{CHI}$ conference on human factors in computing systems, Montreal

Russell S, Norvig P (2009) Artificial intelligence: a modern approach, 3rd edn. Prentice Hall Press, Upper Saddle River

Sarker S (2011) How "sociotechnical" is our IS research? An informal assessment and a possible way forward. In: AIS SIG Phil Workshop on reconciling the social and technical in information systems research, Shanghai

Schlagwein D, Hu M (2016) How and why organisations use social media: five use types and their relation to absorptive capacity. J Inf Technol 32(2):194-209

Schmidhuber J (2015) Deep learning in neural networks: an overview. Neural Netw 61:85-117

Silver D et al (2017) Mastering the game of go without human knowledge. Nature 550(7676):354

Tumbas S, Berente N, vom Brocke J (2018) Digital innovation and institutional entrepreneurship: chief digital officers' perspective of their emerging role. J Inf Technol (JIT), forthcoming

vom Brocke J, Rosemann M (2014) Business process management. In: Wiley Encyclopedia of Management (ed) Management information systems. Van Nostrand Reinhold, New York

vom Brocke J, Fay M, Schmiedel T, Petry M, Krause F, Teinzer T (2017) A journey of digital innovation and transformation: the case of Hilti. In: Oswald G, Kleinemeier M (eds) Shaping the digital enterprise. Springer, Cham, pp 237-251

Wahlster W (ed) (2013) Verbmobil: foundations of speech-to-speech translation. Springer, Heidelberg

Willcocks L, Lacity M, Craig A (2015) The IT function and robotic process automation. The outsourcing unit working research paper series, London School of Economics, Paper 15/05

Williamson OE (1975) Markets and hierarchies: analysis and antitrust implications. A study in the economics of internal organization. Free Press, New York

Winter R, Bichler M, Heinzl A (2015) Teaching. The little brother of research. Bus Inf Syst Eng 57(6):345-348 